\title{
Noise Makes a Hole in My Ear-using Metaphors as Means to Expose Perceptions of Noise among Young Children
}

\author{
Gila Russo-Zimet ${ }^{1}$ \\ ${ }^{1}$ Levinsky College of Education, Tel-Aviv, Israel \\ Correspondence: Dr. Gila Russo-Zimet, Levinsky College of Education, Israel.
}

Received: September 27, 2016

Accepted: October 12, 2016

Available online: November 9, 2016

doi:10.11114/ijsss.v4i12.1972

URL: http://dx.doi.org/10.11114/ijsss.v4i12.1972

\begin{abstract}
The research aim is to understand how young children perceive noise by using metaphoric tools. The study was held according to a phenomenological qualitative paradigm of multiple case studies. Sixty five-years-old children participated in the study. Three research tools were chosen: The Metaphorical Collage (Russo-Zimet, 2015); a tool based on psycho-physical and verbo-gestural metaphor (Merleau-Ponty, 1962[1945]; Cienki \& Müller, 2008); and a tool based on the power of the source domain in creating a metaphor (Lakoff \& Johnson, 1980). An analysis of the children's answers shows that children have a deep complex understanding of the concept of noise. Three relate to the physical concept, and three relate to environmental effects on their life:

1). Noise moves - running, stopping and turning around, 2). Noise is composed of a fast movement, 3). Noise needs multiplicity, 4). Noise is made by man and nature, 5). Noise effects poorly on our body, 6). Noise made by crying and screaming has a negative effect on children. They may not use scientific terms like: sound waves, amplitude, frequency and volume, however, they describe noise as a sound wave, understand that there are frequencies, recognize internal and external noise and understand that man and nature are responsible to noise.
\end{abstract}

Keywords: noise, metaphor tools, concept understanding, early childhood

\section{Introduction}

In recent years, studies conducted, attributed importance to the voice of children in various subjects. Listening to children's voice is not only a way to acknowledge their right to be heard, but also to contribute to knowledge and insight in subjects that are related to their life (Fargas-Malet, McSherry, Larkin \& Robinson, 2010).

In addition to interviews, stories and observations, this study used metaphorical tools and developed a research methodology that involves children actively in the research (Einarsdottir, 2007).The tools in this study include visual and verbal metaphorical aspects that are based on the children's choice of visual imagery and literal metaphors to understand and explain the concept.

Noise as a concept was chosen for several reasons. The phenomenon of noise is intensified and it affects our world and our quality of life. Some claim that noise has an impact on quality of life, ability to learn, develop and that it affects the development of the individual. Moreover, noise is a complex physical psychological-ecological phenomenon - its effect depends on circumstances and previous experiences of the person who hears it - therein lays its complexity and the subjectivity in understanding noise. Everyone has some knowledge of it. However, for one person noise may sound agreeable whereas for another it would be considered loud (Gibson, 1966, 1979; Mazer, 2010).

What is children's perception of noise? What is the place noise takes up in the child's world? Does the child perceive noise as background noise, environmental noise, or as an inner noise inside him?

\subsection{Noise in the Child's World and Its Effect}

Research shows that noise is created by unexpected sounds that cause changes in the physiological and psychological state of one who is exposed to it. It was also found that a correlation exists between environmental sounds and mental situations (Mazer, 2010).

Most studies that observed young children were based on a physiological-medical point of view and the effect noise has on the child's cognitive development. The influences of noise on the cognitive components among young children were examined: memory, reading, listening and motivation. It was found that long term memory and reading are very much 
affected by noise. However, it was found that there is a link between noise and the way information is stored and presented in memory (Passchier-Vermeer, 2001).

A research that deals with the effects noise has on children reports the dangers children face whilst they are exposed to noise (Bistrup, 2001). According to this report conducted in Copenhagen the effect noise has on children begins in early childhood. Symptoms such as hyper sensitivity, restlessness, hearing difficulties, difficulty to function in noisy places and inner noise that disturbs concentration were found in young children. Also noticeable was a difference between the ways children react to noise and ways to avoid elements that interrupt the development of the young child.

Speech perception ability in noisy environments was shown to be significantly, but weakly, related to age, implying the presence of other, possibly environmental factors, in speech perception development (Zhaoli, Yun, Kai \& Dan, 2013).

Many studies about noise focused on the effects of outside noise, for example, (Pujol, et.al, 2014; Moore, Pete \& Sygal, 2015).Studies that examined what noise means to a child from the children's point of view were not found. In recent years there are more studies that aim at exposing the child's point of view about concepts, phenomenon and research questions relevant to the child's world (Clark, 2004; O'Kane, 2004). Listening to the children's voice contributes to knowledge and understanding issues from the child's world (Brooker, 2001).

The younger the children the more important it becomes to examine unique methods that encourage them to take part in the research and express their perceptions as authentically as possible - thus contributing to data collecting process (Christensen \& James, 2000).

This study examined children's perception of noise through metaphors that encourage young children to conduct a conversation. Following is a preview of metaphorical tools as means to expose understandings among young children. It is based on research literature that shows that children are able to use metaphors (Bullough, 1991; Clark, 1988; Güven, 2008; Katz, 1996; Marshall, 1990; Woodwar, 1991).

\subsection{Metaphoric Understanding in Early Childhood}

As part of the child's development in early childhood so does concept understanding develops: he receives, codes and represent reality as he knows it from his close environment, and the interpretation dictates the way he perceives the world around him. Therefore the child's point of view represents reality as he understands, explains and interprets it (Bronfenbrenner, 1989; 2005).

The metaphor is perceived as a conceptual-constructive mechanism of reality. Metaphors can determine the way points of view and concepts appear (Gentner \& Bowdle, 2008; Fauconnier \&Turner, 2008).

Metaphors reflect a way of thought and understanding consciousness in multimodal of representations: language (Cameron, 2008), pictures (Forceville, 2008), gesture (Cienki \& Muller, 2008) and music (Zbikowski, 2008).

By using metaphors a process of mediation occurs and enables a meaningful learning and expansion of thinking and expression at any age and any topic (Lekoff \& Johnson, 1980; Lakoff, 2008; Gibbs \& Matlock, 2008)

Studies show that children "manufacture" metaphors intuitively from the moment they start speaking and are able to understand simple metaphors at the age of 4 (Keil, 1986; Vosniadou, 1987). It is commonly believed that even before children start learning in classrooms they are able to point out similarities between objects from different realms. Even more, children may engage in concepts such as loud-quiet not just literally in detecting differences in sounds but also adapt them metaphorically to colors and moods (Gardner, 1974).

Studies about cognitive development observed the understanding of metaphors and their development among children. Following those studies, researchers discussed the connection between the child's cognitive skills and linguistic aspects. Studies show that analogy is significantly important to the process of learning (Gentner, 1983; Gentner \& Markman, 1997).

There is a connection between the metaphoric process and the analogical ability because transferring knowledge from one realm to another is executed by analogies. This ability depends on cognitive maturity, which is developed with age (Keil, 1986; Vosniadou, 1987). It is no wonder then that with age comes better understanding of analogies and using metaphors (Vosniadou \& Schommer, 1998).

In order to understand metaphor, children need to understand the idea behind the metaphor and be aware of the conceptual ideas and their cognitive context. Understanding and creating metaphors are based on a rich and developed conceptual knowledge of the subjects that are being compared in the metaphor. Lack of knowledge will cause misunderstanding. Therefore, metaphors that deal with conceptual subjects that fit the level of knowledge held by the child will be understood (Gentner \& Markman, 1997; Vosniadou \& Schommer, 1998). 
Furthermore, the metaphor enables the child to acquire new knowledge and understand new phenomenon. It enables transferring knowledge from a familiar place to a less familiar place and thus makes itself a cognitive mechanism (Keil, 1986).

Two elements affect metaphoric understanding in early childhood:

(1) The basis the metaphor leans on attribute and relation metaphors are based on external similarities between objects. The "easy" metaphors are based on attribute, external similarities whereas the "hard" metaphors engage in abstract relations between the objects. For example, the child may understand the metaphor "a hair is like spaghetti", but cannot understand the metaphor "my heart is like a coreless apple". Understanding the second example requires an understanding of relationships (and not a physical characteristic), which is developed at a much more advanced stage (Vosniadou, 1987).

(2) The relationship between the concept and metaphor-closeness or distance from the level of clarity and definition of the limits of the conception: the more defined and clear the borders are, the better the child would understand it. The more the linguistic form that the metaphor is presented with resembles the origin on which it is based the better the understanding (Gardner, 1974; Vosniadou, 1987). For example, a child can understand the sentence "rain is like snow" better than "the rain is like tears" (Vosniadou \& Ortony, 1986).

\section{Research Questions}

How do five-year-old children perceive noise?

How do metaphors contribute to reveal young children's understanding of the concept of noise?

\section{Research Method}

The study was held according to a phenomenological qualitative paradigm of multiple case studies aimed at describing and explaining behaviors and perceptions of the research participants from their own point of view.

The findings' analysis is interpretive, and deals with building meanings rising from the findings' interpretation.

\section{Participants}

The study included sixty children who attended five preschools. All come from medium or high socio-economic status. The preschools are located in the center or the north of the country.

\section{Research Tools}

Three research tools were chosen to understand children's perception of noise.

(1) The Metaphorical Collage (Russo-Zimet, 2015) - It is an expressive tool that reveals meanings and employs metaphor in visual representation as a means of communication.

Following are two examples of collages and the children's explanations.

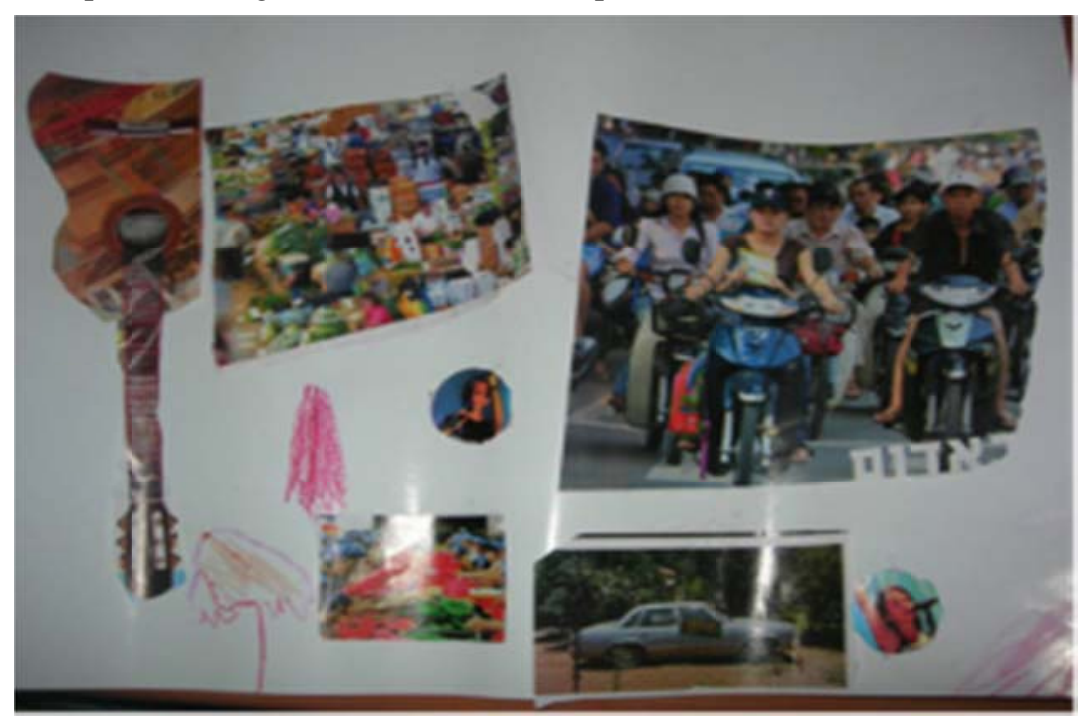

Collage No. 1 
In Collage no. 1, the child chose seven images to describe noise. - People riding motorcycles. The child explains: "many people on the road turn the gas on in their motorcycles and it makes a lot of noise". The lower right side of the collage is a picture of a running car. The child explains: "cars go on the road and make noise". In the collage's center is a picture of a marketplace with people, vegetables and boxes: "It's a big factory. Inside it is a lot of noise". The images show that the child understands the sources of external noise in his surroundings.

On the left is a guitar - "When you play it, it makes nice and noisy sounds". On the lower right side, is a singer holding a microphone and singing and in the middle - a female singer: "when there's a microphone and people sing it makes a loud noise". These three chosen images refer to noise in a different context. The child emphasizes through his choices volumes of sounds from pleasant to unpleasant.

In the center of the collage is a factory an assembly line: "People's creations. When they work, they make an action, and that makes noise". In this choice, the child emphasizes noise as a product of an action that people are making. Every person's action makes noise. "Lots of people" make a lot of noise.

In order to demonstrate the differences between children in understanding the subject and in their perspective on noise I will present another collage.

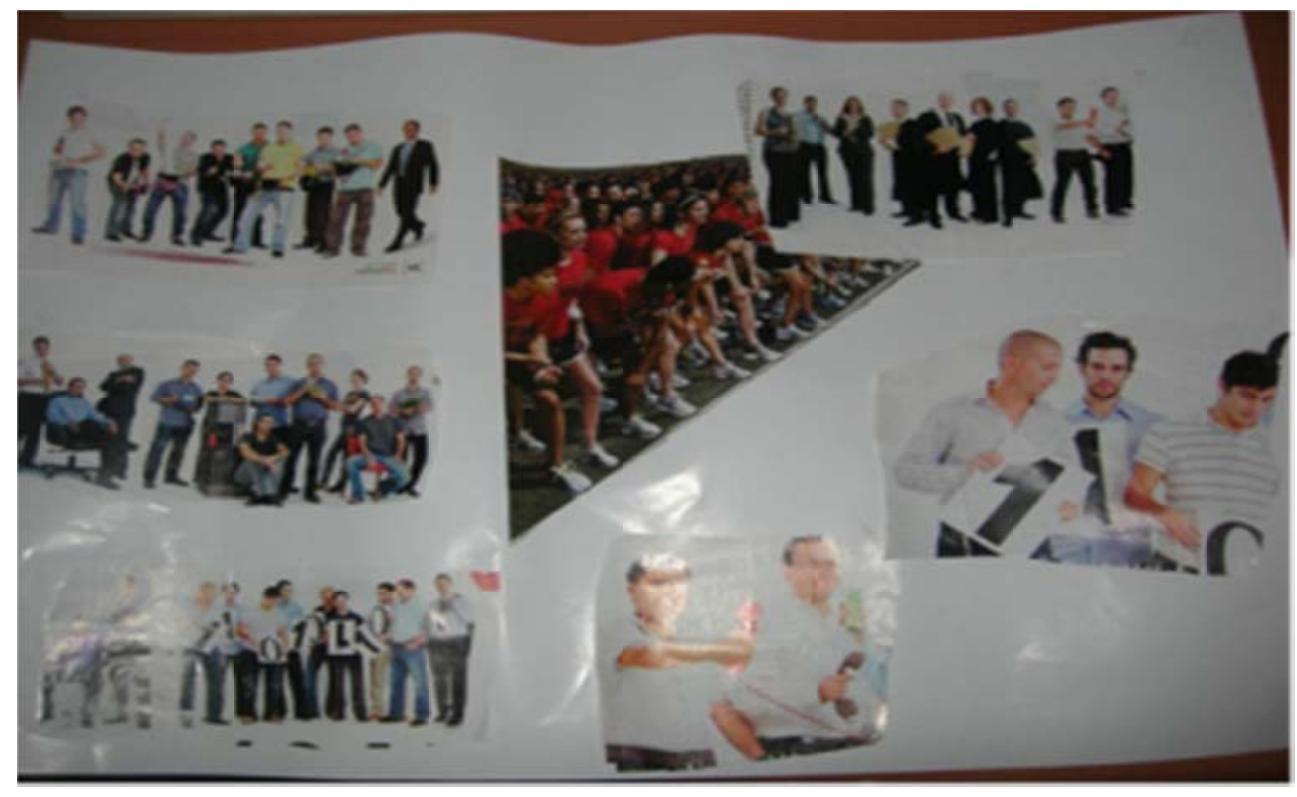

Collage No.2

In collage No. 2, all the images represent noise through people. The child chose only men in certain situations. She explains: "When lots of people run and talk it makes noise"; "When there are a lot of people together they talk, shout. It makes a hole in my ears, a terrible noise"; "Even three people together shout and make noise". When we interpret this collage, it is obvious the child sees people, especially men, as the source of noise. According to her people (namely, men) are the source of noise.

The collages stood at the base of the conversation that developed with the researcher about noise. In the conversation, the metaphors that the children used were identified and analyzed.

Researcher: Who causes noise?

S: Sometimes when I watch TV at home, I turn the volume on too loud. Dad gets angry and says it's noisy, it wakes mom up, so I turn it down. This way I can't hear anything and I have to go see an ear doctor.

Researcher: What does the noise sound like?

S: Lion's roars and all kinds of other animals like an elephant or a crocodile. Also like a noise that a train makes and a garbage truck.

Researcher: How can noise be reduced?

S: Turn it down. Like the sound on the television, you have to press right or left. Right pushes forward and left pushes backwards and then there's quite and everybody settles down.

The metaphor "I turn it on loud" emphasizes a person's ability to control noise. Interpreting images of noise "Lion's roars and all kinds of other animals like an elephant or a crocodile. Also like a noise that a train makes and a garbage 
truck" - images of big animals strengthen the child's perception that noise is strong and intimidating. The big vehicles emphasize noise as a big and possibly powerful thing.

The metaphor "turn it down" - indicates that the child perceives noise as a changeable action. The noise moves from being weak and strong.

(2) The second research tool is based on psychophysical metaphor, which is anchored in the connection between cognitive science (Merleau-Ponty, 1962[1945]; Lakoff \& Johnson, 1999), or as research literature refers to it verbo-gestural metaphors (Cienki \& Müller, 2008). The children were asked to point a body part that represents noise and explain. All children were asked: "Where in the body do you feel noise and why?"

Researcher: Where do you feel noise?

M: In the back of my head.

Researcher: In the back of your head?

M: Yes, the noise is coming from the back of my head because the heart beats loudly.

Researcher: Where in the body do you feel noise?

Y: I don't know.

Researcher: You can show me.

$\mathrm{Y}$ (points at her stomach): From here.

Some of the children could explain their choices while others could not explain their intuitive choices. In analyzing the child's response "The noise comes from the back of my head because the heart beats loudly", the child emphasizes the noise as strong and external, as something that penetrated the body. The following description of findings shows many differences between children in choosing body parts, which indicate different effects noise has on them.

(3) The third tool is based on understanding the power of the source domain in creating a metaphor on the understanding of concepts and was based on the famous research of Lakoff \& Johnson (1980). The children were asked to choose images representing noise from three source domains: colors, animals and natural phenomenon. The chosen subjects are characterized by a rich and developed structure and are well known to young children. Each child was individually asked: If you have to choose choose? Why? For example: (color, animal, natural phenomenon) to explain what noise is, which would you

Researcher: If you have to choose a natural phenomenon to explain what noise is, what would you choose?

$\mathrm{T}$ : Noise is like wind and rain.

Researcher: Why is noise like wind and rain?

$\mathrm{T}$ : Because the wind makes a sound like... (The child moves her hands and taps on the table).

The child refers to noise as something external, changing and that makes different voices.

The three tools in this study were aimed at gathering information from the children about their perceptions of the concept of noise.

All tools were analyzed in order to identify children's perceptions of noise as a concept. The analysis addresses two aspects: the physical elements of the concept definition and the ecological environmental elements of the concept of noise.

\section{Research Process}

The first stage of this study was a pilot that included four children attending a preschool in the northern part of the country. The study included using a metaphorical collage to gather information. The children were asked to make a collage that they think represents noise. After it was completed, they were individually asked to explain what images they chose and why they chose them to describe noise in order to try to understand how they perceive the concept of noise. The answers were recorded and analyzed by the researcher.

The second stage of the research included 21 children (14 girls and 7 boys) aged five to five and a half. They came from a high socio-economic status and attended three preschools located in the center and north of the country. The teachers in the preschools chose the children who participated in the study; they asked who would like to make a collage and speak to the researcher. The children who were chosen were the ones who showed interest in taking part in the research. All 21 participants were given the three research tools: they were asked to make a collage and have a conversation about it; each of the children were asked a direct question: "Where in your body do you feel noise and why?" Finally, they were asked to 
choose four source domains and explain why each of them chose a specific domain to describe and represent the concept of noise. The answers were recorded by the teachers and given to the researcher, who analyzed them.

The third stage included 35 additional children who attended four preschools located in the center and north of the country. The information was gathered by the teachers during the children's activities in the yard. They asked each of the children: "Where in the body do you feel noise and why?" The children's responses were accurately recorded by the teachers and given to the researcher. A conceptual mapping that included content analysis of the children's responses was conducted.

Each of the tools was presented in the following order: the collage was presented first. The collage was made in a group of four children. After it was completed, each child explained separately to the researcher why he chose the metaphor he used in the collage. The researcher kept a close record of all the explanations the children provided, and asked for clarifications when they were needed. After these explanations, each child was asked two more questions regarding the other research tools. The first was: "Where in your body do you feel the noise?" and the second was a request to complete the following sentence: "If you have to choose (color, animal, natural phenomenon) to explain what noise is, which would you choose? Why?"

All the questions were aimed at trying to recognize how young children perceive noise; what images they use to describe it; how they believe it is caused; what effects it has on them and their immediate environments; how they use metaphors in order to explain the concept of noise.

\section{Ethics}

The identities of the children who participated in the study remained anonymous.

\section{Findings}

\subsection{How Do Children Understand Noise}

An analysis of the children's answers shows that 5-year-old children have a deep complex understanding of the concept of noise. They may not use scientific terms like: sound waves, amplitude, frequency and volume, however, they describe noise as a sound wave, understand that there are frequencies, recognize internal and external noise and understand that man and nature are responsible to noise.

A. Noise as a sound waves concept: (1) movement of noise (running, turn around);

(2) Noise energy (activity as a source of noise, for example, playing, walking);

(3) volume of noise (high, low).

B. Noise as environmental phenomenon (1) The source for noise is people and nature;

(2) Crying and screaming are annoying noises.(3) Noise has a negative effect on our body

(4) Noise is a negative phenomenon that children generally deal with by ignoring it or by talking loudly or quietly.

Here are six insights that came up from the children's responses and reflect their concept of noise. Three relate to physical concept, and three relate to environment effects on their life.

\subsubsection{Noise Moves - Running, Stopping and Turning Around}

The sound of the voice was expressed by the children in words and sentences such as: "backwards", "stopping", "going everywhere", "running", "turning around". L. knew that there is a connection between sound and movement and accordingly she chose the lamps image in her collage and explained: "when the lamps move [gesturing with her body and arms right and left]". S. described the movement of sound by using an image of a washing machine: "when the machine turns it makes noise [circling his arms]". S., M. and L. described the movement of sound by using a car metaphor: "the cars go backwards", "a car stops if it can, and it goes everywhere". The noise "moves", so we can therefore characterize noise as one of three situations (as the children expressed): backwards, forward and in a circular motion.

\subsubsection{Noise Has a Fast Movement}

The participants described the speed when they chose a person or an object to represent noise with while making their collage. They chose, for example, an image of a motorcycle going fast. S.: "a motorcycle goes fast [clicks his tongue]". L.: "cars drive fast on the road"

\subsubsection{Noise Needs Multiplicity}

In their opinion, volume is caused by quantity (lots, a lot) for example - S.: "lots of people drive on the road [...]". A. described noise by using a metaphor about sports: "When lots of people run". Or by using plural verbs: "(they are) turning on the gas in their motorcycles", "when (they are) plying", "when a lot of people are together they talk", "even three people together shout and make noise". 


\subsubsection{Noise Is Made by Man and Nature}

Here are some examples of people's actions that children pointed out as causing noise: S.: "when you stomp your foot it makes strong noises". L.: "when you sing it makes a strong noise [...] when there's a microphone and you sing it makes a strong noise [...]".Children used the words "strength" and "strong" to describe noise. They also said that play, stomp, knock, walk, flush make noise: "when you stomp your foot", "bang with the hammer", "when you go pee you flush the toilet", "when you cant's stop the car", "you take a pen, you draw and then you pull down", "the hair dresser is cutting the women's hair. She is sitting like I sit when dad is cutting my hair. It makes zzzzz", "when you break the glasses it makes noise", "you play the piano", "when you play the recorder", "when there's a microphone and you sing [...] when you play there are sounds". Noise also comes from the outside, from our surroundings "there's noise in the gardens and in the farm $[\ldots]$ motorcycles $[\ldots]$ when you play an instrument $[\ldots]$ when ice breaks it makes noise", "the dog barking makes noise"...

\subsubsection{Noise Effects Poorly on Our Body}

S. said: "it feels unpleasant in my body [...] it really irritates me [...] it's very alarming for me and for everyone [...] I close my ears [...] it doesn't hurt very much". M. explains: "it feels like a pain in the ears. You feel dizzy and you don't understand anything". L. pointed out at her stomach and said: "there's no quite [...] when someone shouts and no one is listening there's no quite". And G. said: "I feel noise all over my body. And it hurts on the inside like a blow". P: "when my baby wakes up it's good music. When it cries it's not a good music", "you feel pain in your ears [...] it makes a hole in your ears, a terrible noise". "The clock goes tic-tac and it wakes us up in the morning [...]. The noise makes a hole in the head, a hole in the ears. M. claims, "M. makes noise with her hands on the little batons and it makes a hole in my head". One of the children pointed at her stomach and said, "There are butterflies". Some mentioned ears ("because it hurts when there's shouting"), the mouth ("vocal chords"), teeth, legs ("because you stomp them") and hands ("because you clap"). Some children mentioned concretely a noise the body makes in different situations, for example the heart "because it beats", and some used metaphoric language: the noise "penetrates our body". L. explained: "the heart causes noise cause it's what's inside [...] it comes from the throat"

The effects of noise on the children's body was conceptualized mainly by the question that all the children were asked: Where in your body do you feel noise and why?

The following table sums up the children's answers.

Table 1. Frequency of Children's Answers about Body Parts Representing Noise

\begin{tabular}{llc}
\hline \multicolumn{2}{c}{ Place in the body } & Frequency \\
\hline 1 & heart, chest & 14 \\
2 & Limbs. legs, hands & 12 \\
3 & belly; stomach & 11 \\
4 & ear & 19 \\
5 & Mouth, tooth. & 6 \\
6 & head, forehead, nape, neck & 5 \\
7 & shoulder & 1 \\
8 & few limbs together ,all our body & 1 \\
& Total & 60 \\
\hline
\end{tabular}

According to the table, the heart is the most mentioned body part. The limbs are the second most mentioned body part, and the stomach is at third place.

\subsubsection{Noise Made by Crying and Screaming Has a Negative Effect on Children}

According to the children, noise is crying and screaming, "When someone shouts and no one is listening there's no quite". S. explains (almost without mediation): "I like making noise so mother screams at me [...] I like when my brother bites me and makes noise when he screams. When he sees me coming to pick him up from day care he starts screaming and throws himself on the floor [...] when I watch Ariel he screams because he wants mommy [...] He starts screaming that he wants to stay home with daddy, because daddy goes to work. I really like that mommy has a baby in her stomach. He screams in my ear. I hear that he eats [demonstrates with sounds and gestures]. I really like it when my brother comes to my school. He likes me and doesn't like it when I go". The children offered two ways to deal with noise - to either ignore it or take an opposite action. L. says: "I ignore the noise [...] I whisper" 
In conclusion, the findings show that there is a deep understanding of the concept of noise among young children. Noise is a fast movement and needs multiplicity. It is made by men and nature and affects our body. Crying and screaming have a negative effect on our body and can be dealt with by ignoring and silence.

It is important to point out that all the children that took part in this research used at least one metaphor in explaining the concept of "noise". However, we found a difference between choosing metaphors and the way they explained them.

Moreover, not every child discussed the overall complexity of the concept and its many aspects. Many differences were found in children's understanding of noise: Some widely defined the concept and tied it to their own internal world and some only dealt with the narrow concept of the definition.

\section{Discussion}

The goal of this study was to examine children's understanding of the concept of noise by using metaphorical tools. These two goals are intertwined: understanding the concept of noise and the metaphoric tools that were chosen as means of encouraging children to have conversations in order to determine how they understand the concept of noise. That is why two issues should be discussed: the perceptions of 5-year-old children on the concept of noise, and metaphor as research tool.

These findings show that 5-year-old children have the ability to understand the concept of noise and the ability to use metaphorical language. They are able to convey ideas from one conceptual field to another, as well as describe noise through a wide verity of images.

No previous studies were found regarding understanding the concept of noise from children's point of view. However, research literature discussed immensely in children's understanding of scientific concepts (Piaget, 1969).

This research found that 5-year-old children have a deep understanding of the concept. They perceive noise as a moving sound that has variable volumes and is caused by men and his environment. They attribute its influence on their lives as a negative phenomenon. And they also find solutions to dealing with it.

Not all the children coped with all aspects and some could not explain their choices. As presented in the findings many differences were found in understanding the concept of noise by using metaphors. Some defined the concept widely and tied it to their own inner world and some referred to a narrow aspect of the definition or a small part of it. We chose to explain these differences between the children by four explanations:

The first refers to the children's ability to choose a metaphor to describe noise and point out similarities between objects and not always being able to explain their choices. This explanation is validated by other researches about metaphors (Gentner, 1983; Gentner \& Markman, 1997; Keil, 1986; Vosniadou, 1987; Winner, Engel, \& Gardner, 1980).

For young children the similarity between physical-external resemblances is much more prominent than the similarity in the way they relate, and therefore they will notice it. The closer these subjects are the better the children understand the metaphor.

Strengthening this insight is the fact that according to the research findings children perceived it as "the opposite of silence". One of the participants explained her revulsion of noise "because they are shouting"; she claimed, "When you speak you make noise" and added: "I like quiet". Another participant explained her perception of noise being opposite to quiet: "when someone's shouting and nobody's listening and there's no quiet". Metaphors that include opposite concepts from the same field will be interpreted and understood by young children better than other concepts.

It was found that children can understand and notice more than just the different tones between noise and quiet, but rather they can metaphorically match them with color, mood etc. This process strengthen Keil's (1986) claim that development of metaphor ability is being done on the basis of domain by domain.

The second explanation is anchored in the linguistic development of a child at the age of five. The child is required to explain a scientific phenomenon in words. Moreover, it is possible that the lack of success some children experienced, the partial answers or the failure to explain is caused by a poor verbal ability some of them have (Vosniadou, 1987). Some of them understood intuitively what was needed from them, but this understanding did not manifest itself verbally.

Since the development of a metaphorical ability is reciprocal to linguistic abilities, the ability to provide an appropriate explanation can only be delivered when the linguistic ability develops. The metaphoric understanding should be based in young children in order for them to understand metaphors (Lakoff \& Johnson, 1980; Vosniadou, 1987).

The third explanation lays in the connection between metaphoric ability and analogical thinking ability and general perception of knowledge. This approach is restricted by Keil (1986) who claims that the ability to think analogically affects metaphoric ability, but these are not similar processes. He thinks that analogical ability is based on a hierarch 
linear non-changing structure that is common to all children whereas metaphoric ability is not consistent to all children. It could be the reason why the same metaphor can be understood in different ways and it depends on a number of factors - the circumstances, in which it is displayed, the identity of the person introducing it, the identity of the person receiving it and the children's inner world.

The final explanation has to do with the way information is gathered, that is, the tools used. The children were given source domains to represent noise: colors, animals, natural phenomenon, and food. They were also asked to point out a body part that they thought represented noise. The knowledge of the conceptual ideas compared by metaphors has an important role in successfully creating and explaining metaphors.

Metaphors that include conceptions that match the children's level of knowledge would be better understood by them (Vosniadou, 1987). Children interpret the comparison between two objects as fully compatible in all their elements, for example, noise and animals. The research displayed several source domains assuming that children know "something" about each of these subjects. However, the comparison between noise and each of the subjects was perceived differently in the eyes of the child.

The research findings indicate that using the source domains "human body" and "animals" are more efficient in explaining noise than "color" or "food". The answer may be in the claim that the ability to distinguish between a still object to a live one and between men and animal is the first source domain to be acquired by children, and therefore, metaphors that include objects from these subject matters will be acquired earlier, like "a hole in the head", or when the child clicked his tongue to demonstrate noise (Gardner, 1974; Gentner, 1983; Keil, 1986; Tourangeau \& Sternberg, 1981; Vosniadou, 1987).

The research findings support the understanding that the source domains in this study are not on the same level of proximity to the child's conceptual development. Research emphasize that the closer the source domains are to each other, the metaphor would be better understood by the child. The more defined and clear the boundaries between the categories compared in the metaphor, the easier the child would perform a transfer between them and develop his metaphoric skills. One of the factors that contribute to the development of metaphoric skills is how tight and confined the category boundaries are (Keil, 1986).

It is possible that matching the source domains color, natural phenomenon and food the researched question was wrong. The source domain "human body" is the closest to the target range - noise. The first noise we hear is the one made by our bodies, and that would enable children to use it, not always metaphorically.

\section{Did Metaphor as Research Tool Enable Young Children to Expose their Understanding}

The purpose of the three tools was to encourage discourse and to expose hidden understandings of noise by using images and metaphors throughout the discourse. Here is a review of each tool with its advantages and disadvantages.

The first tool - expression by connection to the body (psychophysical metaphor) its purpose was to bypass children's linguistic limits. The children were asked to point out a source domain - the place in their bodies where they feel noise. They all responded quickly: some pointed at the heart; others on the mouth, some chose the stomach or limbs and some said they feel noise all over their body. The following conversation was accompanied by gestures that came through in changes in tone and volume; in some cases children expresses noise in an aggressive manner. Sometimes they chose to tap at the table or add sounds. Body movement and tone of voice served as "completion" to the missing text. Using the body while speaking, not as gestures but rather as metaphors, is a unique aspect that emphasizes its multidisciplinary nature. This phenomenon emphasizes the ability of the metaphor.

Choosing the body part in the question "where in the body do you feel noise?" is a metaphor that enables a personal explanation related to the child's world. Moreover, children heard a noise in their stomach and covered their ears at the same time. Using this demonstration emphasizes what is being said and makes a valuable, necessary, creative base to verbal metaphors that help the mapping process between the source domain and the target range (Cienki \& Muller, 2008). These gestures are to be viewed as metaphoric conceptual gestures. Their contribution to the mapping process is in combining visual and hearing conceptualization. These gestures are considered metaphoric gestures even if they are not accompanied by speaking. By choosing the place of noise in the body, the children chose to emphasize emotional and social aspects in their lives regarding noise.

The second tool enabled choosing visual images (metaphoric collage). Children chose it to characterize qualities noise holds. It enabled them to choose images of noise such as: animals, structures, objects, plants etc. For instance, M.'s collage had an image of a lion, as well as a room with two children playing with animals. Y. chose an image of floor and a book and said: "when you throw it on the floor it makes noise". The children were able to choose answers out of a variety of images or remember answers already known to them. The images "reminded them", exposed them to 
information and enabled them a choice. Collage makes it possible to bring the far closer, narrow the gaps and break through the limits of thinking and understanding (Brockelman, 2001).

The third tool - the source domains: color, animal, food and natural phenomenon exposed mainly causes of noise and volume of noise. The children tried to find similarities between the source domain and the target range but were left with the conceptual level: "noise is like a roaring lion".

We will point out that in choosing animals and natural phenomenon the children expresses themselves better than in choosing color or food. Therefore, not every source domain fits every concept. It is better to find source domains that allow in character and relations to describe the researched object.

We believe that the research contributes to: (a) understanding the concept of noise among young children; (b) introducing the possibilities that lay in using metaphors as a mechanism to expose children's points of view.

The different tools we used may contribute to early childhood educators in other implications where they would like to expose children's understanding and perceptions. Encouraging a growing awareness of educators to the big contribution using metaphors has, may contribute to classroom discourse - as a thinking tool, a teaching tool and an aid in teaching. It will enable to identify children's intuitive knowledge and better understand their world. A dialogue with a child using metaphors allows a friendly and non-intimidating approach.

\section{References}

Association between Ambient Noise Exposure and School Performance of Children Living in an Urban Area: A Cross-Sectional Population-Based Study. Urban Health, 91(2), 256-271.

Bistrup, M. L. (Ed.). (2001). Health effects of noise on children and perception of the risk of noise. Copenhagen, Denmark: National Institute of Public Health.

Brockelman, T. P. (2001). The frame and the mirror: On collage and the Postmodern. Evanston, IL: Northwestern University Press. Bronfenbrenner, U. (1979). The ecology of human development: Experiments by nature and design. Cambridge: Harvard University Press.

Bronfenbrenner, U. (1989). Ecological Systems Theory. Annals of Child Development, 6(2), 187-249.

Bronfenbrenner, U. (2005). Making human beings human: Bioecological perspectives on human development. Thousand Oaks: Sage Publications.

Brooker, L. (2001). Interviewing children. In G. MacNaughton, S. A. Rolfe, \& I. Siraj-Blatchford (Eds.), Doing early childhood research: International perspectives on theory and practice (162-177). Buckingham, UK: Open University Press.

Bullough, R. V. (1991). Exploring personal teaching metaphors in preservice teacher education. Journal of Teacher Education, 42(1), 43-51.

Cameron, L. (2008). Metaphor and talk. In R. W. Gibbs (Ed.), The Cambridge handbook of metaphor and thought, 197-211.

Christensen, P., \& James, A. (2000).Researching children and childhood: Cultures of communication. In P. Christensen, \& A. James (Eds.), Research with children: Perspectives and practices (1-9). London and New York: Falmer Press.

Cienki, A., \& Müller, C. (2008).Metaphor, gesture, and thought. In R. W. Gibbs (Ed.), The Cambridge handbook of metaphor and thought, 483-501.

Clark, A. (2004). The mosaic approach and research with young children. In V. Lewis, M. Kellett, C. Robinson, S. Fraser, \& S. Ding (Eds.), The reality of research with children and young people, 142-156.

Clark, C. M. (1988). Asking the right questions about teacher preparation: Contributions of research on teacher thinking. Educational Researcher, 17(2), 5-12.

CMC, Regional Universitary Hospital of Besançon (CHRU de Besançon), 2 place Saint Jacques, 25030 Besançon Cedex, France.

Einarsdottir, J. (2007). Research with children: Methodological and ethical challenges. European Early Childhood Education Research Journal, 15(2), 197-211.

Fargas-Malet, M., McSherry, D., Larkin, E. \& Robinson, C. (2010). Research with children: Methodological issues and innovative techniques. Journal of Early Childhood Research, 8(2), 175-192.

Fauconnier, G., \& Turner, M. (2008).Rethinking metaphor. In R. Gibbs (Ed.), The Cambridge handbook of metaphor and thought, 53-66. 
Forceville, C. (2008). Metaphor in pictures and multimodal representations. In R. Gibbs (Ed.), The Cambridge handbook of metaphor and thought, 462-482.

Gardner, H. (1974). Metaphors and modalities: How children project polar adjectives onto diverse domains. Child Development, 45(1), 84-91.

Gentner D., Bowdle B. (2008). Metaphor as structure-mapping. In Gibbs (Ed.), The Cambridge handbook of metaphor and thought, New York: Cambridge University Press.

Gentner, D. (1983). Structure-mapping: A theoretical framework for analogy. Cognitive Science, 7(2), 155-170.

Gentner, D., \& Markman, A. B. (1997). Structure mapping in analogy and similarity. American Psychologist, 52(1), 45-56.

Gibbs, R. W., \& Matlock, T. (2008). Metaphor, imagination, and simulation: psycholinguistic evidence. In R. Gibbs (Ed.), The Cambridge handbook of metaphor and thought, 161-176.

Gibson, J. J. (1966). The senses considered as perceptual systems. Boston, MA: Houghton Mifflin.

Gibson, J. J. (1979). The ecological approach to visual perception. Boston, MA: Houghton Mifflin.

Güven, B. (2008). Experience, instruction, and social environment: Fourth and fifth grade students' use of metaphor. Social Behavior and Personality, 36(6), 743-752.

Katz, A. (1996). Teaching style: A way to understand instruction in language classrooms. Cambridge, UK: Cambridge University Press. In K. M. Bailey, \& D. Nunan (Eds.), Voices from the language classroom, 57-87.

Keil, F. C. (1986). Conceptual domains and the acquisition of metaphor. Cognitive Development, 1, 73-96. http://dx.doi.org/10.1016/S0885-2014(86)80024-7

Lakoff, G., \& Johnson, M. (1980). Metaphors we live by. Chicago, IL: University of Chicago Press.

Lakoff, G., \& Johnson, M. (1999). Philosophy in the flesh: The embodied mind and its challenge to western thought. New York: Basic Books.

Marshall, H. H. (1990). Metaphor as an instructional tool in encouraging student teacher reflection. Theory into Practice, 29(2), 128-132. http://dx.doi.org/10.1080/00405849009543443

Mazer, S. E. (2010). Music, noise, and the environment of care: History, theory, and practice. Music and Medicine, 2(3), 182-191. http://dx.doi.org/10.1177/1943862110372773

Merleau-Ponty, M. (1962). Phenomenology of perception (trans. C. Smith). New York: Humanities Press.

Moore, R., Pete, J. R., \& Sygal, A. (2015). Development of auditory selective attention: Why children struggle to hear in noisy environments. Developmental Psychology, 51(3), 353-369. http://dx.doi.org/10.1037/a0038570

O'Kane, C. (2000). The development of participatory techniques: Facilitating children's views about decisions which affect them. In P. Christensen, \& A. James (Eds.), Research with children: Perspectives and practices (136-159). London and New York: Falmer Press.

Passchier-Vermeer, W. (2001). Effect of noise. In M. L. Bistrup (Ed.), Health effects of noise on children and perception of the risk of noise, 47-68.

Piaget, J. (1969). Science of education and Psychology of the child. New York: Orion Press

Pujol, S., Levain, J. P., Houot, H., Petit, R., Berthillier, M., Defrance, J., Lardies, J., Masselot, C., \& Mauny, F. (2014).

Russo-Zimet, G. (2016)).The "Metaphorical Collage" as a Research Tool In in the Field of Education. Universal Journal of Educational Research, 4(4), 802-811. http://dx.doi.org/10.13189/ujer.2016.040417

Russo-Zimet, G., Avivi-Dan, Y., \& Gilat, Y. (2009).Metaphoric collage as research tool in education. Dapim, 48, 197-163.

Tourangeau, R., \& Sternberg, R. J. (1981).Aptness in metaphor. Cognitive Psychology, 13, 27-55. http://dx.doi.org/10.1016/0010-0285(81)90003-7

Vosniadou, S. (1987). Children and metaphors. Child Development, 58(3), 870-885. http://dx.doi.org/10.2307/1130223

Vosniadou, S., \& Brewer, W. F. (1987).Theories of knowledge restructuring in development. Review of Educational Research, 57(1), 51-67. http://dx.doi.org/10.3102/00346543057001051

Vosniadou, S., \& Ortony, A. (1986). Testing the Metaphoric Competence of the Young Child. Paraphrase Versus Enactment in: Human Development, 29(4), 223-244 
Vosniadou, S., \& Schommer, M. (1998). Explanatory analogies can help children acquire information from expository text. Journal of Educational Psychology, 80(4), 524-536. http://dx.doi.org/10.1037/0022-0663.80.4.524

Winner, E., Engel, M., \& Gardner, H. (1980). Misunderstanding metaphor: What`s the problem? Journal of Experimental Child Psychology, 30(1), 22-32. http://dx.doi.org/10.1016/0022-0965(80)90072-7

Woodward, T. (1991). Models and metaphors in language teacher training: Loop input and other strategies. Cambridge, UK: Cambridge University Press.

Zbikowski, L. M. (2008). Metaphor and Music. In R. Gibbs (Ed.), The Cambridge handbook of metaphor and thought, 502-524. http://dx.doi.org/10.1017/CBO9780511816802.030

Zhaoli, M., Yun, Z., Kai, W., \& Dan, L. (2013). Evaluation of speech perception in competing noise conditions for normally hearing children, Noise\& Health, 15(64), 178-82. http://dx.doi.org/10.4103/1463-1741.112367

\section{$(\boldsymbol{c c})$ EY}

This work is licensed under a Creative Commons Attribution 3.0 License. 